\title{
Aspectos qualitativos da carcaça e carne ovina são modificados com uso de aspersão de água
}

\author{
Qualitative aspects of the carcass and ovine meat are modified with the use of water spray \\ Karina Aline Mateus*, Moisés Rodrigues dos Santos, Maisa Chiocca, Jocelita de Lima, Tálison Orso, \\ Diego de Córdova Cucco e Julcemar Dias Kessler
}

Universidade do Estado de Santa Catarina, Chapecó, SC, Brasil. *Autor para correspondência: kazootecnista@gmail.com

Submissão:05/11/2018 / Aceite: 05/04/2019

\begin{abstract}
RESUMO
O objetivo desta pesquisa foi investigar os aspectos qualitativos da carne ovina, após a submissão ou não de 20 carcaças à aspersão de água. O experimento foi realizado em delineamento em bloco ao acaso, com dois tratamentos com dez carcaças cada e dez repetições. As carcaças foram submetidas e não submetidas à aspersão de água por 10 horas consecutivas em câmara fria. As análises de qualidade instrumental da carne foram determinadas nos músculos Longissimus thoracis et lumborum (LTL), e ocorreram em dois períodos distintos, inicialmente dentro do período de 24 horas post mortem e após 7 meses de congelamento não industrial. Foram analisados $\mathrm{pH}$, coloração de carne e gordura subcutânea, perda por coç̧ão, capacidade de retenção de água, atividade de água, comprimento de sarcômero, força de cisalhamento e medidas corporais da carcaça. Além destas, foram incluídas a mensurações subjetivas de cor e marmoreio e a análise microbiológica (Escherichia coli). Após as análises, foi observado que nas carcaças aspergidas, o músculo LTL modificou o croma dentro de 24 horas post mortem e a tonalidade após o congelamento ( 7 meses). Além destes, houve aumento na contagem microbiológica $\left(5,9 \times 10^{1} \mathrm{e}\right.$ $\left.4,3 \times 10^{2} \mathrm{UFC} / \mathrm{cm}^{2}\right)$ e no rendimento frigorífico $(48,77 ; 46,28 \mathrm{~kg})$. Contudo, houve maior perda no resfriamento $(4,87 ; 3,27 \%)$. Para carcaças não aspergidas, houve maior declínio de $\mathrm{pH} 2$ horas post mortem (pH 6,9) e menor $\mathrm{pH}$ final após 24 horas (pH 5,6). Entretanto, após o congelamento não houve diferença significativa $(p<0,05)$ entre os tratamentos. Para as outras análises não foi constatada diferença significativa. $\mathrm{O}$ uso ou não de aspersão por 10 horas consecutivas em carcaças ovinas, promove alterações indesejadas nos aspectos qualitativos da carcaça e carne. Neste sentido, não recomendamos o uso prolongado (10 horas) de aspersão em carcaças ovinas.
\end{abstract}

PALAVRAS-CHAVE: fibra muscular, ovinocultura, resfriamento, rigor mortis.

\begin{abstract}
The objective of this research was to investigate the qualitative aspects of sheep meat, after the submission or not of 20 carcasses to water spray. The experiment was carried out in a randomized block design, with two treatments with ten carcasses each and ten replicates. The carcasses were submitted and not submitted to water sprinkling for 10 consecutive hours in a cold chamber. Instrumental meat quality analyzes were performed on the Longissimus thoracis et lumborum (LTL) muscles, and occurred in two distinct periods, initially within the 24-hour post-mortem period and after 7 months of non-industrial freezing. The $\mathrm{pH}$, meat and subcutaneous fat staining, cooking loss, water retention capacity, water activity, sarcomere length, shear force and body measurements of the carcass were analyzed. In addition to these, subjective color and marbling measurements and microbiological analysis (Escherichia coli) were included. After the analysis, it was observed that sputum carcasses, LTL muscle modified chroma within 24 hours post mortem and tonality after freezing ( 7 months). In addition, there was an increase in the microbiological count $\left(5.9 \times 10^{1}\right.$ and $\left.4.3 \times 10^{2} \mathrm{UFC} / \mathrm{cm}^{2}\right)$ and in the refrigerator yield $(48.77,46.28 \mathrm{~kg})$. However, there was greater loss in cooling $(4.87,3.27 \%)$. And in for unprosted carcasses, there was a greater decline in $\mathrm{pH} 2$ hours post mortem ( $\mathrm{pH}$ 6.9) and lower final pH after 24 hours (pH 5.6). However, after freezing there was no significant difference $(p<0.05)$ between treatments. For the other analyzes, no significant difference was found. The use or not of spraying for 10 consecutive hours in ovine carcasses, promotes unwanted changes in the qualitative aspects of the carcass and meat. In this sense, we do not recommend prolonged use (10 hours) of spraying on ovine carcasses.
\end{abstract}

KEYWORDS: cooling, muscle fiber, sheep-raising, rigor mortis. 


\section{INTRODUÇÃO}

No abate comercial, a refrigeração se torna um aspecto crítico de processamento da carcaça dos animais devido a sua influência na qualidade do produto final e aspectos econômicos (VERBEKE et al. 2010). As carcaças são rapidamente arrefecidas, a fim de reduzir o crescimento microbiano e contribuir para segurança alimentar. Porém, o período de exposição das carcaças ao frio contribui com perdas na qualidade e econômicas na cadeia de produção da carne.

A taxa de resfriamento afeta diretamente os processos bioquímicos no post mortem, e influencia o aspecto visual do músculo (ROSENVOLD \& WIKLUND 2011), e na qualidade da carne (LI et al. 2012), disponível ao consumidor. Nos processos bioquímicos post mortem, destaca-se o encurtamento muscular pelo frio das câmaras frias sobre a fibra muscular, e/ou processos de congelamento da carne. Este fenômeno geralmente altera o rearranjo das estruturas musculares e contribui com a menor maciez da carne, e consequentemente acarreta em perdas econômicas à indústria.

$O$ efeito da fase de endurecimento muscular post mortem, pode ser modificado através da alteração do grau de encurtamento muscular. Principalmente com o uso de metodologias de aspersão, conforme já revisadas por PRADO \& FELíCIO (2010), onde o uso de sistemas de aspersão junto ao processo de refrigeração se mostrou eficiente na redução da perda de peso das carcaças. A aspersão de carcaça pode ser definida como a pulverização de água sobre a carcaça em tempo cronometrado com a intenção de reduzir as perdas de peso e, consequentemente, melhorar a qualidade da carne (JONES \& ROBERTSON 1988). Neste sentido, o objetivo deste trabalho foi avaliar os aspectos qualitativos de carne ovina oriunda de carcaças submetidas ou não, à aspersão de água por 10 horas consecutivas, e após o período de 7 meses de congelamento da carne em freezer não industrial (convencional).

\section{MATERIAL E MÉTODOS}

Um total de 20 carcaças de fêmeas ovinas (peso médio de $39,15 \pm 2 \mathrm{~kg}$ ), mestiças Texel $x$ Corriedale (18 meses) aleatoriamente selecionadas foram incluídas no estudo, em outubro de 2016. Os animais foram abatidos, e as carcaças pesadas conforme as práticas normais nas instalações do abatedouro, fiscalizado pelo Sistema de Inspeção Federal. As mensurações corporais foram realizadas conforme a metodologia descrita por OSÓRIO \& OSÓRIO (2005).

Após 0 abate, as carcaças foram aleatoriamente pesadas e distribuídas em dois grupos: 10 carcaças aspergidas (CASP) e 10 carcaças não aspergidas (CNASP), alocadas em blocos inteiramente casualizados, e mantidas em câmara fria por 24 horas. As aspersões foram realizadas com água clorada (1,5 ppm), borrifadas diretamente sobre as carcaças por 10 horas consecutivas, com ciclos de aspersão cronometrados de 60 segundos de duração.

No período post mortem foram mensurados na região da $12^{\mathrm{a}}-13^{\mathrm{a}}$ costela, o $\mathrm{pH}$ muscular $(\mathrm{LTL})$ com peagâmetro portátil com eletrodo de penetração (HANNA, HI 99163), a coloração da gordura subcutânea aos 45 minutos, e às $2,4,6,8,10$ horas, a coloração da carne (LTL) aos 45 minutos, e às 2, 4, 6, 8, 10 e 24 horas com auxílio do colorímetro Konica Minolta (CR 400). Os resultados foram expressos como a média de três medidas.

Para avaliar as condições microbiológicas das carcaças foi utilizado como referência, presença ou ausência da enterobactéria Escherichia coli. O material biológico foi coletado pelo método não destrutivo (NZFSA 2008), obtido diretamente da superfície de oito carcaças aleatoriamente selecionadas dentro dos tratamentos (três carcaças sem aspersão, três com aspersão e duas carcaças controles não incluídas anteriormente nos tratamentos propostos). Logo após a coleta, o material biológico foi mantido em tubos de ensaio com solução de Brain Heart Infusion (BHI, KASVI, Brasil) e refrigerados $\left(4^{\circ} \mathrm{C}\right)$ e encaminhados imediatamente ao laboratório de microbiologia.

No laboratório, o material biológico coletado foi diluído em seis séries decimais e distribuído $1 \mathrm{ml}$ em ágar MacConkey (KASVI, Brasil), em seguida foram incubados em estufa a $37^{\circ} \mathrm{C}$ por 24 horas, conforme metodologia descrita por LENAHAN et al. (2009). A contagem foi realizada após 0 isolamento, homogeneização e suspensão (solução padrão da escala Mc Farland) de seis colônias morfologicamente características de E. coli e em seguida, dispostas em ágar Müller-Hinton (Oxoid). Após a incubação de 24 horas, a $37{ }^{\circ} \mathrm{C}$ foram realizadas as contagens das bactérias com auxílio de um contador de colônias (Phoenix EC - 589). Os resultados foram multiplicados pelo respectivo fator de diluição e unidade de área amostrada $\left(100 \mathrm{~cm}^{2}\right)$, e expressa em unidades formadoras de colônias (UFC/ $\left./ \mathrm{cm}^{2}\right)$.

Para avaliar o comprimento de sarcômero foram removidas e clivadas duas amostras do músculo LTL $(2 \mathrm{~cm} \times 1 \mathrm{~cm} \times 0,5 \mathrm{~cm})$. Removidas em cinco carcaças de cada tratamento na região da $12^{\mathrm{a}}-13^{\mathrm{a}}$ costela, 1 hora após o início dos tratamentos em câmara fria, e repetido o mesmo procedimento 24 horas após a 
refrigeração. As amostras foram coletadas, e fixadas conforme a técnica adaptada de RODRIGUES et al. (2007). Na sequência foram processadas, conforme a metodologia adaptada de TOLOSA et al. (1976) e mensurados dez sarcômeros através do software $\left(\right.$ Image $\left.{ }^{\circledR}\right)$, seguindo a técnica adaptada de SLOSS \& KEMP (1978).

A capacidade de retenção de água foi determinada conforme a metodologia de CAÑEQUE \& SAÑUDO (2005). Na sequência, as mesmas subamostras utilizadas para de determinar a capacidade de retenção de água foram homogeneizadas por 3 minutos, e dispostas $(2 \mathrm{~g})$ no leitor Aqualab ${ }^{\circledR}$ (Lite, Brasil) para determinar a atividade de água, em duplicata.

A perda por cocção foi determinada após a remoção uma fatia do músculo LTL de aproximadamente $2 \mathrm{~cm}$ de espessura, em seguida pesadas e assadas até a temperatura interna atingir $72{ }^{\circ} \mathrm{C}$. O resultado foi obtido através da subtração do peso inicial pelo peso final divido pelo peso inicial. Para determinar a força de cisalhamento, as amostras foram dispostas em duas porções retangulares com altura e largura mensuradas e inseridas no equipamento texturômetro Texture Analyser (TA - XT2I), acoplado ao dispositivo Warner-Bratzler com lâmina de corte em "V". Foi utilizada a velocidade de ensaio de $10 \mathrm{~mm} / \mathrm{segundo}$ até que o dispositivo entre em contato com a amostra, após o contato a velocidade de ensaio era reduzida a 1 $\mathrm{mm} /$ segundo. Os resultados obtidos foram expressos em $\mathrm{kgf} / \mathrm{cm}^{2}$.

Após as análises de qualidade instrumental, as respectivas subamostras restantes (CASP e CNASP) foram embaladas em sacos plásticos, e posteriormente mantidas por 7 meses em regime de congelamento em freezer não industrial (Frost free Eletrolux) com intervalo de temperatura de -16 a $-18{ }^{\circ} \mathrm{C}$. Nesta etapa do experimento, buscou-se avaliar a qualidade instrumental da carne, após tecnicamente aproximar-se de uma situação realística, em que o consumidor adquiriu a carne ( $L T L)$ oriunda de carcaças aspergidas ou não, e em seguida armazenou no congelador não industrial por 7 meses, em temperatura entre -16 a $-18^{\circ} \mathrm{C}$.

Após 7 meses de congelamento não industrial, as amostras foram descongeladas em refrigerador $\left(4{ }^{\circ} \mathrm{C}\right.$ por 24 horas), na sequência, foi determinada novamente a qualidade instrumental da carne com os mesmos protocolos anteriormente utilizados.

Os resultados das variáveis obtidas foram submetidos à análise de variância (ANOVA) e as médias das variáveis foram comparadas pelo Teste $F$, considerando o nível de significância de $5 \%$ de probabilidade. Para as características de $\mathrm{pH}$ e coloração de gordura foram realizadas medidas repetidas no tempo e os dados microbiológicos foram comparados com os valores descritos na resolução RDC $n^{\circ} 12$, de 2 de janeiro de 2001 da Agência Nacional de Vigilância Sanitária (ANVISA 2001).

\section{RESULTADOS E DISCUSSÃO}

O estudo mostrou que o uso ou não de aspersão em carcaça ovina por 10 horas consecutivas, proporciona alterações nas características físico-químicas e microbiológicas. Os benefícios da redução de perdas evaporativas da carcaça durante a refrigeração, não foram encontrados neste estudo.

Os animais apresentaram peso vivo (PV) e espessura de gordura média (post mortem) de 39,03 \pm $4,68 \mathrm{~kg}$ e $39,26 \pm 4,84 \mathrm{~kg}$ e $2,85 \pm 2,11 \mathrm{~cm}$ e $3,64 \pm 2,36 \mathrm{~cm}$ para carcaças aspergidas e não aspergidas, respectivamente. Os valores médios para pesos de carcaça quente (PCQ), peso de carcaça fria (PCF), rendimento comercial (RC) (Tabela 1) e medidas métricas na carcaça não diferiram estatisticamente $(p<0,05)$ entre os tratamentos (Tabela 2). Contudo, as carcaças aspergidas perderam mais peso por evaporação (PPE) $(p=0,0070)$ após 24 horas de refrigeração, e apresentaram um maior rendimento frigorífico ( $p=0,0359)$ (Tabela 1$)$, comparado a carcaças sem aspersão. As medidas objetivas e subjetivas de carcaça não apresentaram diferenças estatísticas (Tabela 2), em ambos os tratamentos.

Em média, as carcaças aspergidas perderam significativamente mais peso $(1,6 \%)(p<0,05)$ durante a refrigeração $(4,87 \% \pm 0,84)$ do que carcaças que não receberam pulverização de água $(3,27 \% \pm 1,43)$. Resultados opostos foram descritos por PRADO \& FELÍCIO (2010), com a redução de 1,63\% na perda por evaporação em carcaças bovinas aspergidas em relação à média de tratamentos não pulverizados, e por BROWN et al. 1993 ao avaliar o uso de aspersão intermitente em carcaças de ovinos. Na pesquisa foi verificado que, a temperatura média e a velocidade do ar da câmara ao longo do período avaliado foram de $1,1 \pm 0,93{ }^{\circ} \mathrm{C}$ e $1,4 \pm 0,81 \mathrm{~m} / \mathrm{s}$, respectivamente, o que pode estar associadas às maiores perdas evaporativas das carcaças aspergidas. De acordo com BROWN et al. 1993 a água interna dos tecidos pode difundir-se para o meio externo em função dos gradientes de concentração da água, que age como uma força motriz.

Para os valores de $\mathrm{pH}$ inicial médio de carcaças aspergidas e não aspergidas não houve diferença estatística (Tabela 3). Os valores foram, respectivamente, de 6,7 $\pm 0,31$ e 6,5 $\pm 0,12$, porém, após 4 horas 
post mortem houve aumento $(\mathrm{P}=0,0142)$ na taxa de declínio do $\mathrm{pH}(\mathrm{pH}=7,0)$ nas carcaças que não receberam aspersão (Figura 1). Acredita-se que a presença da água na superfície da carcaça após as aspersões contribui para a redução da temperatura interna muscular. Este fato, favorece o processo de transformação do glicogênio muscular em ácido lático, e como consequência, ocorre a queda do pH (ENGLAND et al. 2013). Contudo, a ausência da água na superfície da carcaça proporcionou aumento no $\mathrm{pH}$ muscular durante o período post mortem.

Tabela 1. Valores médios dos parâmetros para rendimentos de carcaças ovinas (Texel x Corriedale) refrigeradas, aspergidas (CASP) e não aspergidas (CNASP) por 10 horas durante a refrigeração.

Table 2. Average values for the yield parameters of sheep carcasses (Texel x Corriedale), sprayed (CASP) and non-spayed (CNASP) for 10 hours during refrigeration.

\begin{tabular}{lccccc}
\hline Variáveis & CASP & DP & CNASP & DP & p<0,05 \\
\hline PV $(\mathrm{kg})$ & 39,03 & 4,68 & 39,26 & 4,84 & NS \\
PCQ $(\mathrm{kg})$ & 18,98 & 1,88 & 18,14 & 2,24 & $\mathrm{NS}$ \\
PCF $(\mathrm{kg})$ & 18,06 & 1,81 & 17,56 & 2,35 & $\mathrm{NS}$ \\
PPE (\%) & $4,87^{\mathrm{a}}$ & 0,84 & $3,27^{\mathrm{b}}$ & 1,43 & $*$ \\
RC $(\mathrm{kg})$ & 46,39 & 2,13 & 44,78 & 3,20 & $\mathrm{NS}$ \\
RF $(\mathrm{kg})$ & $48,77^{\mathrm{a}}$ & 2,35 & $46,28^{\mathrm{b}}$ & 3,09 & * \\
\hline
\end{tabular}

$\mathrm{PV}=$ Peso Vivo; $\mathrm{PCQ}=$ Peso de carcaça quente; $\mathrm{PCF}=$ Peso de carcaça fria; PPE = Perda de peso por evaporação; $\mathrm{RC}=$ Rendimento comercial; $\mathrm{RF}=$ Rendimento frigorífico, NS = Não significativo. $\mathrm{DP}=$ Desvio Padrão. Médias seguidas de letras distintas na linha diferem entre si $(p<0,05)$, pelo Teste $F$.

Tabela 3. Valores médios dos parâmetros de medidas objetivas e subjetivas nas carcaças ovinas (Texel $x$ Corriedale) refrigeradas, aspergidas (CASP), não aspergidas (CNASP) por 10 horas post mortem.

Table 4. Average values of objective and subjective measures of the parameters in refrigerated, sprayed (CASP) and non-sprayed (CNASP) sheep carcasses (Texel $x$ Corriedale) for 10 hours post mortem.

\begin{tabular}{|c|c|c|c|c|c|}
\hline Medidas objetivas & CASP & DP & CNASP & $\mathrm{DP}$ & $p<0,05$ \\
\hline CPM (cm) & 55,2 & 3,26 & 54,9 & 2,84 & NS \\
\hline PFP (cm) & 13,2 & 0,77 & 12,91 & 0,71 & NS \\
\hline $\mathrm{CPP}(\mathrm{cm})$ & 37,4 & 1,17 & 37,00 & 0,81 & NS \\
\hline $\operatorname{LPN}(\mathrm{cm})$ & 11,0 & 0,62 & 10,82 & 0,73 & NS \\
\hline PTX (cm) & 29,6 & 0,99 & 29,17 & 1,23 & NS \\
\hline EE & 4,20 & 0,48 & 3,9 & 0,51 & NS \\
\hline $\mathrm{EG}(\mathrm{mm})$ & 2,8 & 2,11 & 3,64 & 2,36 & NS \\
\hline CFC & 3,90 & 0,61 & 3,8 & 0,48 & NS \\
\hline $\mathrm{AOL}\left(\mathrm{cm}^{2}\right)$ & 10,4 & 1,13 & 10,79 & 2,00 & NS \\
\hline \multicolumn{6}{|l|}{ Medidas subjetivas } \\
\hline $\mathrm{MAV}^{*}$ & 2,85 & 0,62 & 2,85 & 0,52 & NS \\
\hline $\mathrm{TXV}^{*}$ & 2,80 & 0,42 & 3,00 & 0,40 & NS \\
\hline $\mathrm{CLV}^{*}$ & 3,55 & 0,55 & 3,50 & 0,52 & NS \\
\hline
\end{tabular}

$\overline{\mathrm{CPM}}=$ Comprimento; PFP $=$ Profundidade de perna; $\mathrm{CPP}=$ Comprimento de perna; $\mathrm{LPN}=$ Largura de perna; $\mathrm{PTX}=$ Profundidade de tórax; $\mathrm{EE}=$ Estado de engorduramento; $\mathrm{EG}=\mathrm{Espessura}$ de Gordura; $\mathrm{CFC}=$ Conformação; $\mathrm{AOL}=$ Área de Olho de Lombo; MAV = Marmoreio visual; $T X V=$ Textura visual; $C L V=$ Coloração visual. $N S=$ Não Significativo. DP $=$ Desvio Padrão. Médias seguidas de letras distintas na linha diferem entre si $(p<0,05)$ pelo Teste $F$. *índice $1-5$ adaptado de OSÓRIO \& OSÓRIO (2005).

Nos momentos seguintes de avaliação do pH, o comportamento dessa variável foi semelhante, independente da aspersão ou não sobre a superfície da carcaça. No entanto, houve interação entre os tratamentos e o período antes (P1) e após congelamento não industrial (P2) (7 meses) para os valores de $\mathrm{pH}$ final (Tabela 3). Antes do congelamento (P1), as carcaças não aspergidas apresentaram menor média de $\mathrm{pH}(5,6)$ do que carcaças aspergidas (Tabela 3). E ao comparar o pH final dos tratamentos dentro dos períodos ( $\mathrm{P} 1$ e $\mathrm{P} 2$ ), foi observado que em ambos os tratamentos, o período de congelamento reduziu o 
valor médio de $\mathrm{pH}$, que foram de 5,4 e 5,5 para carcaças com e sem aspersão, respectivamente.

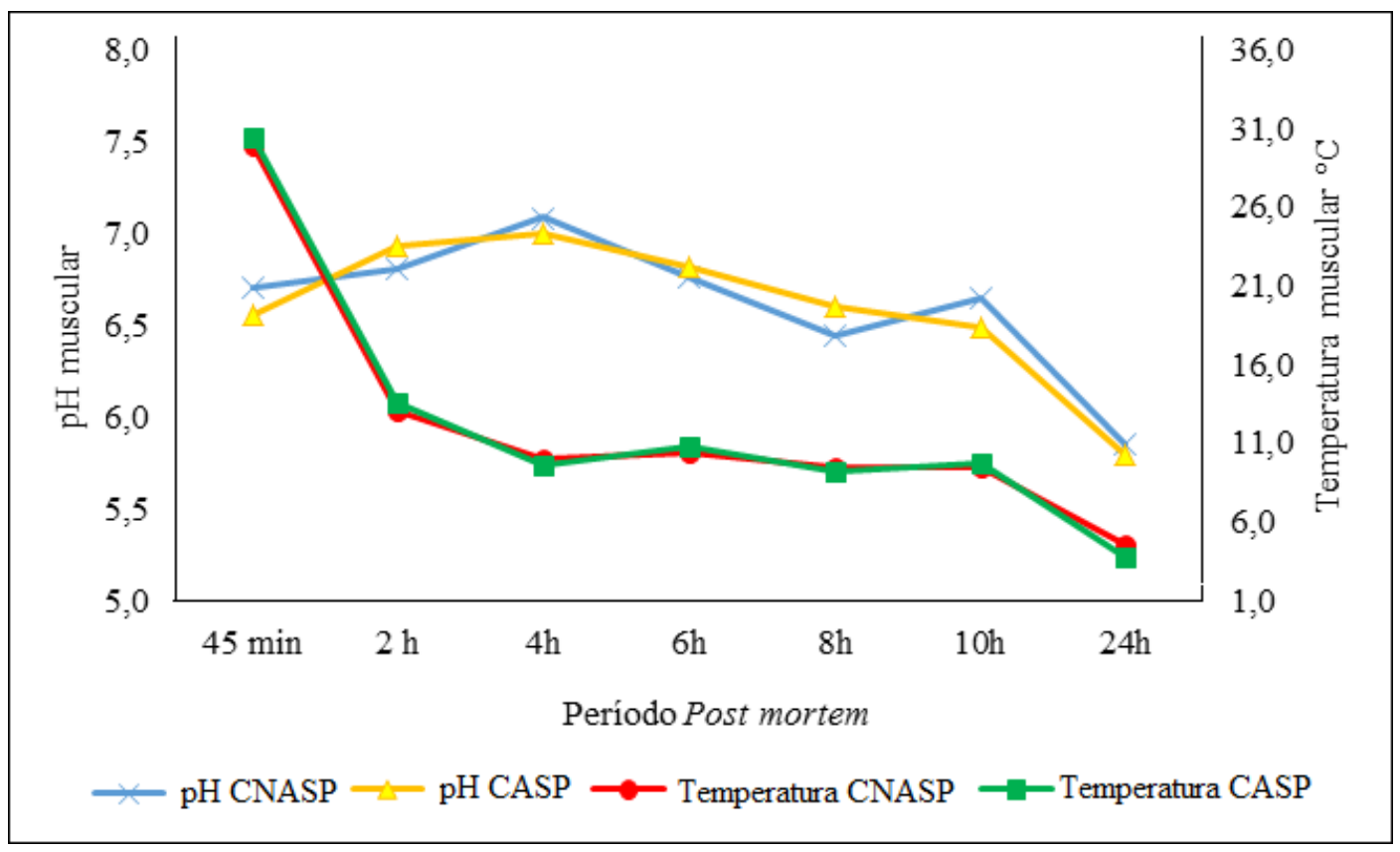

Figura 1. Valores médios de pH e temperatura interna do músculo Longissimus thoracis et lumborum de carcaças aspergidas (CASP) e não aspergidas (CNASP) por 10 horas consecutivas no período post mortem.

Figure 1. Average values of $\mathrm{pH}$ and internal temperature of the Longissimus thoracis et lumborum muscle of sprayed (CASP) and non-sprayed (CNASP) carcasses for 10 consecutive hours in the post-mortem period.

Tabela 3. Valores médios dos parâmetros físico-químicos do músculo Longissimus thoracis et lumborum oriundo de carcaças ovinas aspergidas (CASP) e não aspergidas (CNASP) por 10 horas post mortem em refrigeração e após o período de 7 meses de congelamento não industrial $(P 1=$ período anterior ao congelamento, $\mathrm{P} 2=$ período posterior ao descongelamento).

Table 3. Average values of the Longissimus thoracis et lumborum muscle physicochemical parameters from sheep carcasses sprayed (CASP) and non-sprayed (CNASP) for 10 hours post mortem in refrigeration and after the 7-month non-industrial freezing period $(P 1=$ pre-freezing period, $P 2=$ period after thawing).

\begin{tabular}{lll}
\hline \multirow{2}{*}{ Tratamento } & \multicolumn{2}{c}{ Período } \\
\cline { 2 - 3 } & $\mathrm{P} 1$ & $\mathrm{P} 2$ \\
\hline CASP & $5,74 \mathrm{Aa}$ & $5,49 \mathrm{Ba}$ \\
CNASP & $5,66 \mathrm{Ab}$ & $5,50 \mathrm{Ba}$ \\
\hline
\end{tabular}

Médias seguidas de mesma letra não diferem estatisticamente entre si, maiúscula na coluna e minúscula na linha, pelo teste $\mathrm{F}$ a $5 \%$ de probabilidade.

Após o descongelamento, as carnes oriundas de carcaças aspergidas demonstram médias de $\mathrm{pH}$ mais baixos. LEYGONIE et al. (2011) descrevem que carne submetida ao congelamento e descongelamento tende a apresentar $\mathrm{pH}$ mais baixo. Este fato ocorre em função do aumento na quantidade de íons livres, e a degradação proteica.

À medida que o pH declina, ocorre a aproximação do ponto isoelétrico. Neste ponto, acontece a atração máxima das cadeias laterais de aminoácidos negativos e positivos. Esta aproximação dos filamentos impossibilita a entrada de água, que reduz a capacidade de retenção de água (DEN HERTOGMEISCHKE et al. 1997). Este fator, portanto, pode estar associado ao animal, como a idade ao abate avançada, que por consequência diminui a solubilidade do colágeno e aumenta as ligações entre as fibras e afeta a maciez da carne (MODZELEWSKA-KAPITUŁA et al. 2015), bem como, outros fatores associados à alimentação, sanidade, genética e manejos, conforme já revistos por GUERRERO et al. (2013).

Neste estudo, a capacidade de retenção de água, a perda por cocção e força de cisalhamento não 
sofreram alterações (Tabela 4) com o declínio da taxa de pH, mesmo após o congelamento. BALLIN \& LAMETSCH (2008) descrevem que o tamanho dos cristais de gelo promove danos à fibra muscular no congelamento e, o congelamento lento produz cristais de gelos maiores, o que promove o aumento na desnaturação das proteínas e por consequência maior perda na capacidade de retenção de água. Em nosso estudo, não foram verificadas perdas neste sentido.

Tabela 4. Valores médios dos parâmetros físico-químicos do músculo Longissimus thoracis et lumborum de carcaças ovinas aspergidas (CASP) e não aspergidas (CNASP) por 10 horas post mortem em refrigeração, avaliadas no pré (P1) e pós descongelamento (P2).

Table 4. Average values of the Longissimus thoracis et lumborum muscle physicochemical parameters in refrigerated, sprayed (CASP) and non-sprayed (CNASP) sheep carcasses, for 10 hours post mortem, evaluated pre (P1) and post thawing (P2).

\begin{tabular}{|c|c|c|c|c|c|c|c|c|c|}
\hline & \multicolumn{9}{|c|}{ Variáveis } \\
\hline & $\mathrm{L}^{*}$ & $a^{*}$ & $\mathrm{~b}^{*}$ & $\mathrm{H}^{*}$ & $\mathrm{C}^{*}$ & CRA (\%) & $\begin{array}{c}\mathrm{FC} \\
\left(\mathrm{kgf} / \mathrm{cm}^{2}\right)\end{array}$ & AW & $\begin{array}{l}\text { PPC } \\
(\%)\end{array}$ \\
\hline CASP & 34,12 & 11,51 & 13,15 & 40,02 & 23,66 & 75,98 & 3,05 & 0,763 & 27,87 \\
\hline NASP & 32,79 & 11,07 & 12,19 & 35,69 & 21,02 & 75,91 & 3,17 & 0,753 & 5,86 \\
\hline pValue & 0,335 & 0,400 & 0,087 & 0,226 & 0,007 & 0,671 & 0,558 & 0,508 & 0,472 \\
\hline DP & 0,16 & 0,48 & 0,84 & 0,69 & 0,65 & 0,07 & 0,88 & 0,48 & 0,05 \\
\hline CV & 12,89 & 14,25 & 13,62 & 29,35 & 13,12 & 0,61 & 20,80 & 5,61 & 17,41 \\
\hline & \multicolumn{9}{|c|}{ Período } \\
\hline $\mathrm{P} 1$ & 35,06 & 12,68 & 16,41 & 22,30 & 25,85 & 75,94 & 4.78 & 0,724 & 27,83 \\
\hline P2 & 31,85 & 9,89 & 8,93 & 53,34 & 18,82 & 75,94 & 1,43 & 0,792 & 29,03 \\
\hline pValue & 0,354 & 0,291 & 0,753 & 0,020 & 0,080 & 0,777 & 0,959 & 0,113 & 0,465 \\
\hline DP & 0,12 & 0,13 & 0,08 & 0,38 & 0,17 & 0,009 & 0,12 & 0,18 & 0,05 \\
\hline $\mathrm{CV}$ & 6,23 & 5,74 & 5,91 & 9,41 & 9,23 & 0,48 & 16,22 & 3,88 & 13,33 \\
\hline
\end{tabular}

$\mathrm{L}^{*}=$ luminosidade; $\mathrm{a}^{*}=$ teor de vermelho e $\mathrm{b}^{*}=$ teor de amarelo; $\mathrm{H}^{*}=$ Tonalidade; $\mathrm{C}^{*}=$ Croma; CRA = Capacidade de retenção de água; FC = Força de cisalhamento; $A W=$ Atividade de água; $P P C=$ Perda por cocção; $D P=$ Desvio Padrão. $C V=$ Coeficiente de Variação. Médias seguidas de letras distintas na linha diferem entre si $(p<0,05)$ pelo Teste F.

Os dados dos parâmetros de coloração da gordura subcutânea e LTL (Tabela 5), não apresentaram diferenças $(p<0,05)$ entre os tratamentos no sistema CIE $L^{*}, a^{*}$ e valores de $b^{*}$. Porém, os valores do croma da carne, foram significativamente maiores $(p<0,05)$ para carcaças aspergidas antes do congelamento (Tabela 4), e a tonalidade no pós-congelamento de 7 meses. O aumento no croma e tonalidade podem estar associados à desnaturação proteica que ocorre durante o congelamento, e acrescida da aspersão sobre a carcaça. A desnaturação proteica aumenta à auto-oxidação da mioglobina e posterior perda de das cores desejadas de acordo com LEYGONIE et al. (2012).

As carcaças aspergidas apresentaram contagem microbiológica média para $E$. coli de $5,9 \times 10^{1} \mathrm{e}$

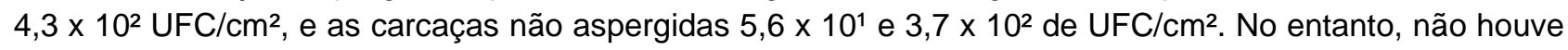
modificação nos valores médios para a variável atividade de água (AW) (Tabela 4). A contaminação bacteriana por $E$. coli foi acrescida nas carcaças que receberam aspersões de água o que provavelmente pode estar relacionado com a contaminação cruzada, via água e manipulação durante o abate. WIKLUND et al. (2010) relataram que caso a carcaça não possua tempo suficiente para secar após a aspersão, o crescimento bacteriano é favorecido, embora a redução superficial de temperatura seja progressiva ao longo do tempo. Assim, pode-se justificar o aumento na contagem bacteriana devido a não oportunizar a secagem completa das carcaças e a redução da carga bacteriana. Este fato ocorre em função das aspersões prolongadas no período post mortem por 10 horas consecutivas e possivelmente implica, na redução da vida de prateleira da carne, pois propicia o crescimento de bactérias indesejáveis.

Os resultados médios para o comprimento de sarcômero foram de 1,84, 1,82 e 1,80 e 1,78 $\mu$ para carcaças aspergidas e não aspergidas, respectivamente, avaliadas dentro do período de 1 e 24 horas post mortem. Não houve diferença significativa entre os tratamentos avaliados. As variações no comprimento de sarcômero possuem relação com as perdas evaporativas das carcaças, porém, neste estudo esta relação não foi verificada.

As carcaças aspergidas aumentaram as porcentagens de perdas evaporativas em relação as não aspergidas, entretanto o sarcômero de ambas permaneceu inalterado, o que corrobora com os resultados de MUCHENJE et al. (2008), que descrevem que o encurtamento pelo frio nem sempre ocorre. Várias 
pesquisas relatam o encurtamento de sarcômero e qualidade de carne sobre 0 efeito da temperatura (DEVINE et al. 1999, KOLCZAK et al. 2003, BEKHIT et al. 2007, WIKLUND et al. 2010). Neste caso, pode estar associado à proteção das fibras musculares conferidas devido à maior deposição de tecido adiposo dos animais abatidos aos 18 meses em ambos os tratamentos.

Tabela 5. Valores médios da coloração da gordura subcutânea (CGS) das carcaças ovinas da raça (Texel $x$ Corriedale) aspergidas (CASP) e não aspergidas (CNASP) com água ao longo do período de 10 horas post mortem em refrigeração.

Table 5. Average values of subcutaneous fat coloring (SFC), sprayed (CASP) and non-sprayed (CNASP) with water, over the period of 10 hours post mortem in refrigerated sheep carcasses (Texel $x$ Corriedale).

\begin{tabular}{llllll}
\hline $\begin{array}{c}\text { Variáveis } \\
\text { CGS }\end{array}$ & \multicolumn{5}{l}{ Tratamentos } \\
\hline $\mathrm{L}$ & $\mathrm{CASP}$ & $\mathrm{DP}$ & $\mathrm{CNASP}$ & $\mathrm{DP}$ & $\mathrm{p}<0,05$ \\
\hline $45 \mathrm{~min}$. & 78,2 & 2,50 & 78,77 & 1,87 & $\mathrm{NS}$ \\
$2 \mathrm{~h}$ & 81,2 & 2,83 & 80,35 & 2,63 & $\mathrm{NS}$ \\
$4 \mathrm{~h}$ & 79,1 & 1,34 & 78,11 & 2,51 & $\mathrm{NS}$ \\
$6 \mathrm{~h}$ & 79,3 & 1,50 & 78,32 & 2,19 & $\mathrm{NS}$ \\
$8 \mathrm{~h}$ & 78,3 & 2,49 & 78,87 & 1,70 & $\mathrm{NS}$ \\
$10 \mathrm{~h}$ & 80,6 & 3,32 & 80,22 & 1,96 & $\mathrm{NS}$ \\
\hline $\mathrm{a}^{*}$ & & & & \\
\hline 45 min. & 2,53 & 1,96 & 1,87 & 1,82 & $\mathrm{NS}$ \\
$2 \mathrm{~h}$ & 1,49 & 1,52 & 1,62 & 0,95 & $\mathrm{NS}$ \\
$4 \mathrm{~h}$ & 2,22 & 1,16 & 2,67 & 0,77 & $\mathrm{NS}$ \\
$6 \mathrm{~h}$ & 2,21 & 1,14 & 2,84 & 1,38 & $\mathrm{NS}$ \\
$8 \mathrm{~h}$ & 2,05 & 1,23 & 2,94 & 1,18 & $\mathrm{NS}$ \\
$10 \mathrm{~h}$ & 2,41 & 2,54 & 2,69 & 1,42 & $\mathrm{NS}$ \\
\hline $\mathrm{b}^{*}$ & & & & & \\
\hline 45 min. & 8,16 & 2,32 & 6,28 & 3,45 & $\mathrm{NS}$ \\
$2 \mathrm{~h}$ & 6,67 & 2,88 & 6,49 & 1,17 & $\mathrm{NS}$ \\
$4 \mathrm{~h}$ & 5,42 & 2,21 & 5,33 & 2,08 & $\mathrm{NS}$ \\
$6 \mathrm{~h}$ & 4,71 & 2,34 & 5,56 & 2,23 & $\mathrm{NS}$ \\
$8 \mathrm{~h}$ & 4,42 & 2,70 & 5,52 & 2,45 & $\mathrm{NS}$ \\
$10 \mathrm{~h}$ & 4,12 & 2,30 & 5,75 & 1,73 & $\mathrm{NS}$ \\
\hline
\end{tabular}

$\mathrm{L}^{*}=$ luminosidade; $\mathrm{a}^{*}=$ teor de vermelho e $\mathrm{b}^{*}=$ teor de amarelo, NS = Não Significativo, DP = Desvio Padrão. Médias seguidas de letras distintas na linha diferem entre si $(p<0,05)$ pelo Teste $F$.

\section{CONCLUSÃO}

Nas condições experimentais adotadas podemos concluir que, o uso de aspersão de água em câmara fria por 10 horas consecutivas sobre a superfície das carcaças ovinas modifica os aspectos de qualidade da carne antes, e após o congelamento não industrial por um período de 7 meses, do músculo (Longissimus thoracis et lumborum). Destaca-se que, após o uso de aspersão na superfície da carcaça houve modificações nos atributos da carcaça e carne, principalmente o aumento das perdas evaporativas da carcaça em 24 horas e a contaminação por enterobactérias. Este fato por sua vez, desaconselha o uso desta metodologia na indústria frigorífica em função do risco sanitário.

\section{REFERÊNCIAS}

ANVISA. 2001. Resolução RDC $\mathrm{n}^{\circ} 12$, de 2 de janeiro de 2001. Disponível em: http://portal.anvisa.gov.br/documents/33880/2568070/RDC_12_2001.pdf/15ffddf6-3767-4527-bfac-740a0400829b. Acesso em: 12 nov. 2016.

BALLIN NZ \& LAMETSCH R. 2008. Analytical methods for authentication of fresh vs. thawed meat - A review. Meat Science 80: 151-158.

BEKHIT AED et al. 2007. Effects of rigor temperature and electrical stimulation on venison quality. Meat Science 75 : 564-574.

BROWN T et al. 1993. Spray chilling of lamb carcasses. Meat Science 34: 311-325.

CAÑEQUE V \& SAÑUDO C. 2005. Estandarización de las metodologias para evaluar la calidad del produto (animal vivo, 
canal, carne y grasa) em los ruminantes. 3.ed. Madrid: INIA. 448p.

DEN HERTOG-MEISCHKE MJA et al. 1997. The water-holding capacity of fresh meat. Veterinary Quarterly 19: 175-181.

DEVINE CE et al. 1999. Effect of rigor temperature on muscle shortening and tenderisation of restrained and unrestrained beef $\mathrm{m}$. longissimus thoracicus et lumborum. Meat Science 51: 61-72.

ENGLAND EM et al. 2013. Exploring the unknowns involved in the transformation of muscle to meat. Meat Science 95: 837-843.

GUERRERO A et al. 2013. Some factors that affect ruminant meat quality: from the farm to the fork. Review. Acta Scientiarum 35: 335-347.

JONES SDM \& ROBERTSON WM. 1988. The effects of spray-chilling carcasses on shrinkage and quality of beef. Meat Science 24: 177-188.

KOLCZAK T et al. 2003. Changes in structure of psoas major and minor and semitendinosus muscles of calves, heifers and cows during post-mortem ageing. Meat Science 64: 77-83.

LENAHAN M et al. 2009. The potential use of chilling to control the growth of Enterobacteriaceae on porcine carcasses and the incidence of E. coli O157:H7 in pigs. Journal Applied Microbiology 106: 1512-1520.

LEYGONIE C et al. 2011. Oxidative stability of previously frozen Ostrich M. iliofibularis packaged under different modified atmospheric conditions. International Journal of Food Science and Technology 46: 1171-1178.

LEYGONIE C et al. 2012. Impact of freezing and thawing on the quality of meat: Review. Meat Science 91: 93-98.

$\mathrm{LI} \mathrm{K}$ et al. 2012. Effect of very fast chilling and ageing time on ultra-structure and meat quality characteristics of Chinese yellow cattle M. Longissimus lumborum. Meat Science 92: 795-804.

MODZELEWSKA-KAPITUŁA M et al. 2015. Water holding capacity and collagen profile of bovine $m$. infraspinatus during post mortem ageing. Meat Science 100: 209-216.

MUCHENJE V et al. 2008. Meat quality of Nguni, Bonsmara and Aberdeen Angus steers raised on natural pasture in the Eastern Cape, South Africa. Meat Science 79: 20-28.

NZFSA. 2008. Sampling. DRAFT Schedule 1: Technical procedures for the national microbiological database. Disponível em: https://www.mpi.govt.nz/nzfoodsafety/. Acesso em: 03 nov. 2016.

OSÓRIO JC DA S \& OSÓRIO MTM. 2005. Produção de carne ovina: técnicas de avaliação - in vivo e na carcaça. 2.ed. Pelotas: UFPEL. 73p.

PRADO CS \& FELÍCIO PE. 2010. Effects of chilling rate and spray-chilling on weight loss and tenderness in beef strip loin steaks. Meat Science 86: 430-435.

RODRIGUES EC et al. 2007. Qualidade e composição química de cortes comerciais de carne de jacaré-do-pantanal (Caiman yacare). Ciência e Agrotecnologia 31: 448-455.

ROSENVOLD K \& WIKLUND E. 2011. Retail colour display life of chilled lamb as affected by processing conditions and storage temperature. Meat Science 88: 354-360.

SLOSS MWBS \& KEMP RLAB. 1978. Veterinary clinical parasitology. 4.ed. lowa: Ames. 247p.

TOLOSA et al. 1976. Manual de técnicas para histologia normal e patológica. 1.ed. São Paulo: EDART. 341p.

VERBEKE W et al. 2010. European beef consumers' interest in a beef eating-quality guarantee. Insights from a qualitative study in four EU countries. Appetite 54: 289-296.

WIKLUND E et al. 2010. Spray chilling of deer carcasses - Effects on carcass weight, meat moisture content, purge and microbiological quality. Meat Science 86: 926-930. 